\title{
Characterization of histomorphological and microbiological changes in tooth pulp to assess post-mortem interval: an observational study
}

Lipsa Bhuyan, Shyam Sundar Behura*, Kailash Chandra Dash, Pallavi Mishra, Niva Mahapatra and Abikshyeet Panda

\begin{abstract}
Background: The rate of decomposition of the organs of the body has been widely studied by forensic pathology experts for the determination of time elapsed after death. But researches pertaining to the dental pulp organ have been very sparse. This study attempts to identify the morphologic and microscopic characteristics of the tooth pulp for over a time period of 2 years with respect to time elapsed since its designated death.

Materials and method: Eight experimental groups consisting of 5 extracted teeth in each group were constituted. The apical foramen was blocked with modeling wax. In groups 1, 2, 3, 4, 5, 6, 7, and 8, dental pulp was extirpated after $24 \mathrm{~h}, 48 \mathrm{~h}, 72 \mathrm{~h}, 1$ month, 3 months, 6 months, 1 year, and 2 years of extraction, respectively. The pulp tissue underwent a standard histological processing and hematoxylin and eosin ( $\mathrm{H} \& \mathrm{E})$ staining. Slides were observed under a light microscope.

Results and discussions: Morphologically, the color of the pulp changed from pink at $24 \mathrm{~h}$ to pale pink by $72 \mathrm{~h}$. The consistency ranged from soft to firm to jelly by $72 \mathrm{~h}$ and later became desiccated and friable by 2 years. Microscopically, a rapid degeneration in the constituents of pulp was seen until $72 \mathrm{~h}$ followed by slowing down beyond 1 month with less histologic variations. Smaller vacuolations were observed in a 24-h PMI pulp which progressively increased filling up the entire stroma by 2 years. The nuclei underwent a series of autolytic changes with increasing time. The odontoblastic layer was seen in some areas for up to 6 months. Microbiological assessment showed Gram-positive staphylococci and streptococci up to 2 years

Conclusion: Estimation of post-mortem interval (PMI) changes in pulp, which is enclosed in a hard structure, composed of enamel and dentin provides the advantage of being studied up to 2 years as compared to other organs. Progressive degradation of the matrix and cellular constituents of the pulp with increased vacuolations were noted in our study, and evaluation of these characteristics can be a cost-effective and simplified additional tool to estimate the PMI.
\end{abstract}

Keywords: Degenerative changes, Dental pulp, Forensic odontology, Post-mortem interval, Putrefaction, Staining characteristics

\footnotetext{
* Correspondence: dr.shyamsb@gmail.com

Oral and Maxillofacial Pathology, Department of Oral and Maxillofacial

Pathology, Kalinga Institute of Dental Sciences, KIIT Deemed to be University,

Campus 5, Bhubaneswar, Odisha 751024, India
}

\section{Springer Open}

(c) The Author(s). 2020 Open Access This article is licensed under a Creative Commons Attribution 4.0 International License, which permits use, sharing, adaptation, distribution and reproduction in any medium or format, as long as you give appropriate credit to the original author(s) and the source, provide a link to the Creative Commons licence, and indicate if changes were made. The images or other third party material in this article are included in the article's Creative Commons licence, unless indicated otherwise in a credit line to the material. If material is not included in the article's Creative Commons licence and your intended use is not permitted by statutory regulation or exceeds the permitted use, you will need to obtain permission directly from the copyright holder. To view a copy of this licence, visit http://creativecommons.org/licenses/by/4.0/. 


\section{Background}

A series of physiologic and biochemical changes caused by the absence of circulation of blood and loss of regulatory mechanisms are evident following the death of an individual. Decomposition of the dead is accomplished by autolytic enzymes initially and progressed by putrefying bacteria leading to degenerative changes which can be comprehended morphologically as well as histologically. Studies have been done to histo-morphologically analyze these degenerative changes in the blood, skin, eyes, sebaceous gland, skeletal muscles, kidney, and liver which helps to interpret the post-mortem interval (PMI) of an individual (Zdravković et al. 2006; Pittner et al. 2016; Kushwaha et al. 2010). Unlike other soft tissues, dental pulp is well protected within the pulp cavity which is bounded by the hard tissues like dentin, enamel, cementum, and jaws. Therefore, it is uncontaminated and majorly unaffected by external assaults (Gawande et al. 2012). While other soft tissues degrade easily, dental pulp is preserved for 4-5 years, thereby prolonging the detection rate of PMI (Manoilescu et al. 2015).

Very limited studies have evaluated the delayed putrefaction potential of the dental pulp tissue as an indicator to estimate the post-mortem interval (Gawande et al. 2012; Carrasco et al. 2017). An attempt has been made to identify the characteristic degenerative cellular and nuclear changes taking place in a hematoxylin and eosin (H \& E)-stained pulp tissue under light microscope. This observational study aims to evaluate the morphologic, histologic, and microbiologic changes that occur in the tooth pulp with respect to the time elapsed since death.

\section{Materials and methods}

An observational study was planned with 8 experimental groups numbered from 1 to 8 consisting of 5 extracted teeth in each group. Handling and analyses on human tissues were executed within the framework of Institutional Ethics Committee, Kalinga Institute of Dental Sciences. A specially designed informed consent was obtained from the participants participating in the study. Forty non-carious premolars that were indicated for extraction during the orthodontic treatment in Kalinga Institute of Dental Sciences were included in the study.

The carious teeth were excluded from the study. The date and time of extraction was noted which was considered equivalent to the time of death. The apical foramen was blocked with modeling wax to simulate the socket of the jaw and act as a barrier from the environmental factors. In groups $1,2,3,4,5,6,7$, and 8 , dental pulp was extirpated after $24 \mathrm{~h}, 48 \mathrm{~h}, 72 \mathrm{~h}, 1$ month, 3 months, 6 months, 1 year, and 2 years of extraction, respectively. The tooth was placed in a shallow depression of a wooden block and was fractured by short, sharp regular blows using a chisel and mallet. The pulp tissue was then separated from the dentin with the help of a probe and a pair of forceps (Fig. 1). Morphological changes of the dental pulp in size, color, and consistency were documented (Fig. 2).

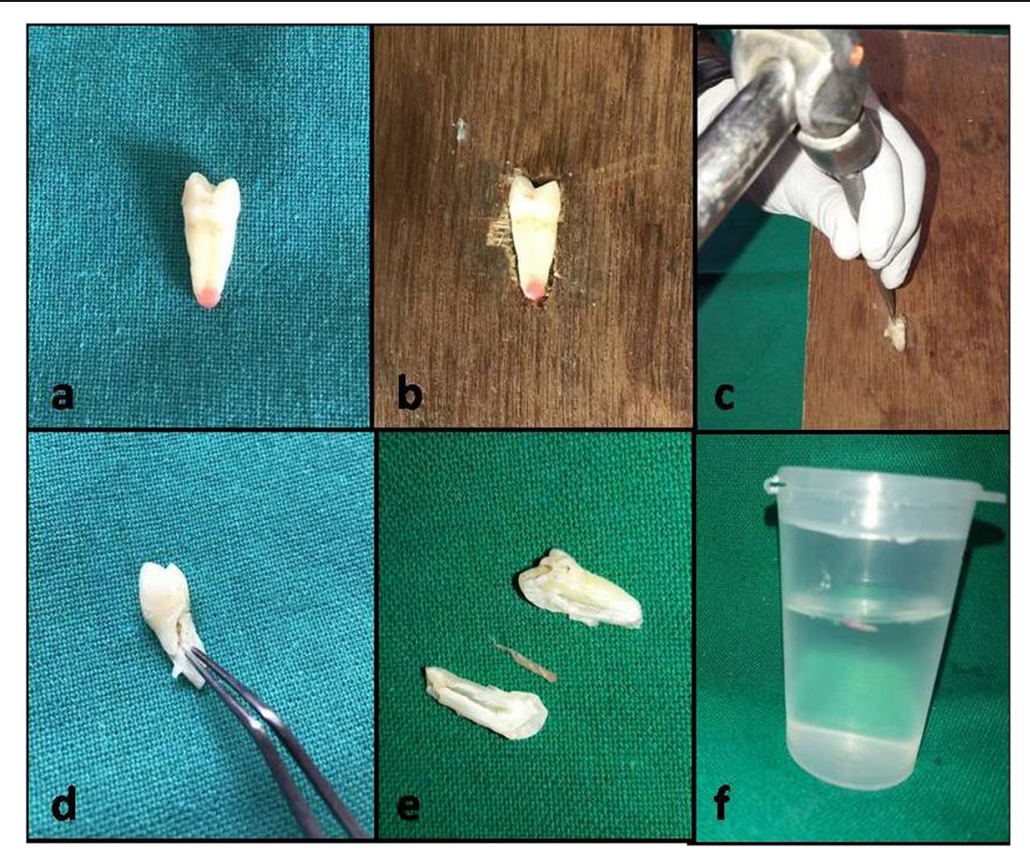

Fig. 1 Procedure for pulp retrieval. a Apical foramen blocked with modeling wax after extraction. $\mathbf{b}$ The tooth placed in the shallow depression of a wooden block accommodating the tooth shape. $\mathbf{c}$ The tooth split with chisel and mallet. $\mathbf{d}$ Pulp retrieval with a pair of forceps. e The retrieved pulp. f Pulp tissue fixed in 10\% buffered formalin 


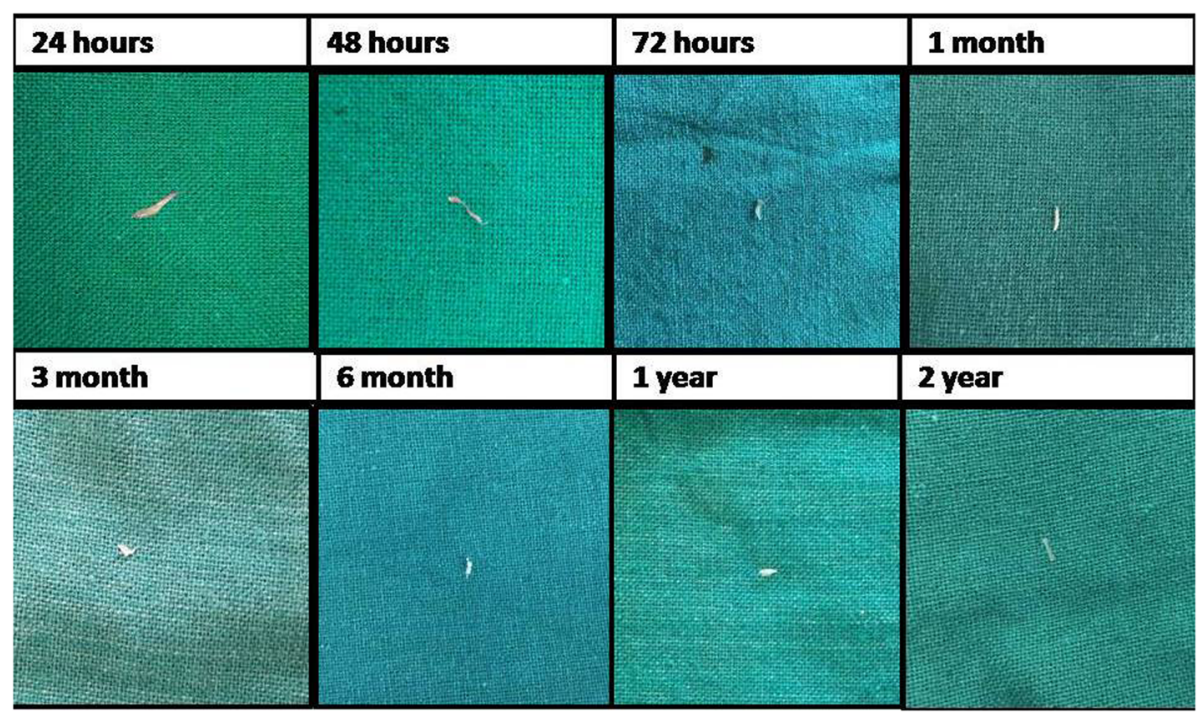

Fig. 2 Morphologic characteristics of the pulp tissue at various post-mortem time intervals

The pulp obtained was then fixed in formalin buffered at $10 \%$. Standard histological processing of dehydration and paraffin embedding was carried out. The tissue blocks were then sectioned and deparaffinized. The slides were stained with routine $\mathrm{H} \& \mathrm{E}$ and Gram stain (Brown and Brenn). The slides were then observed under a light microscope with magnification of $\times 100, \times$ 400 for $\mathrm{H} \& \mathrm{E}$ sections, and $\times 1000$ for Gram-stained sections. The morphologic, histologic, and microbiologic features were identified, qualitatively analyzed, and listed.

\section{Results}

Group 1 with $24 \mathrm{~h}$ PMI showed pulp tissue which was pinkish and soft to firm in consistency. In histology, a homogeneously fibrous connective tissue with few small vacuolations was noticed. The stroma was highly cellular and consisted of plump fibroblasts with basophilic spindle-shaped nuclei containing homogeneous chromatin. Numerous defense cells with deeply basophilic nuclei were found. Endothelial lined blood vessels engorged with red blood cells (RBCs) were seen. An intact odontoblastic layer with numerous odontoblasts was noted in the periphery (Fig. 3).

The pulp tissue with $48 \mathrm{~h}$ PMI belonging to group 2 was dirty pink and had a consistency ranging from soft to firm. Histology showed numerous small vacuolations in homogeneously loose connective tissue stroma with no signs of intercellular matrix degeneration. Numerous fibroblasts with basophilic nuclei, few endothelial lined blood vessels containing few engorged RBCs were also observed. Numerous scattered defense cells with light stained basophilic nuclei were found. The odontoblastic layer was intact and seen at the periphery (Fig. 3).

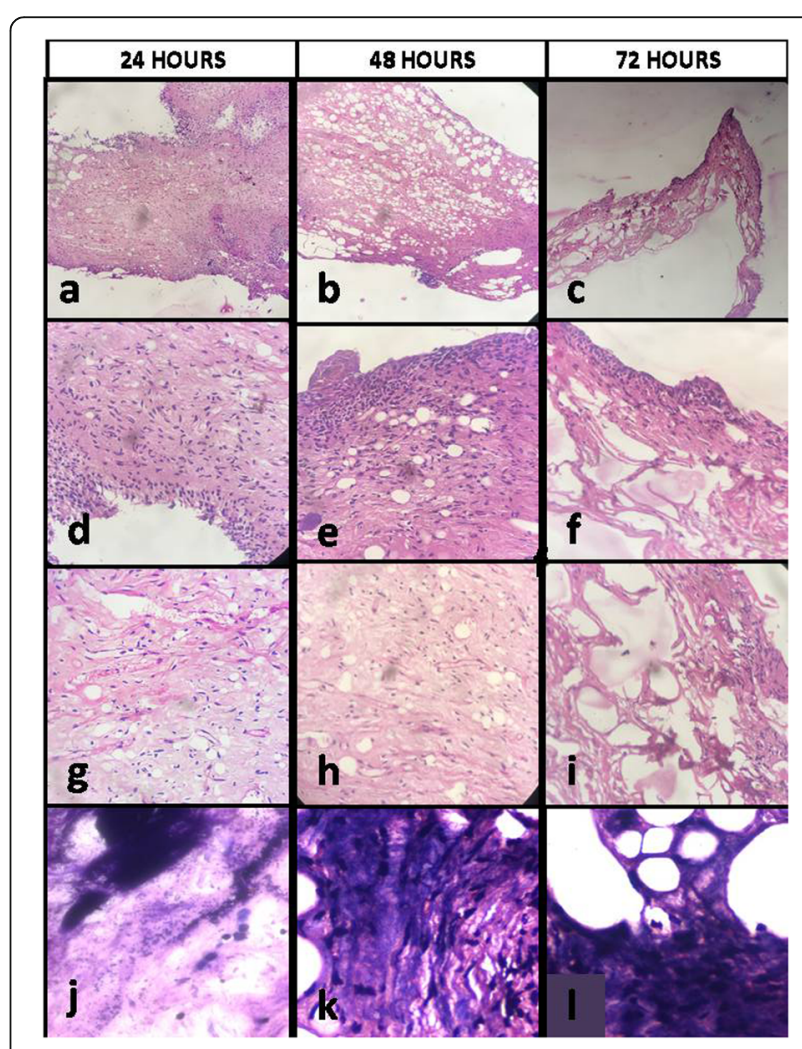

Fig. 3 Histological and microbiological assessment after 24, 48, and $72 \mathrm{~h}$ of extraction. a-c Pictomicrograph shows increasing vacuolations of the ECM with time $(\times 100)$. $\mathbf{d}-\mathbf{f}$ Intact odontoblastic layer seen at the periphery $(\times 400)$. $\mathbf{g}$-i Gradual degeneration of endothelial cells and RBCs $(\times 400)$. $\mathbf{j}-\mathbf{I}$ Tissue Gram stain (Brown and Brenn) highlighting the presence of Gram-positive cocci consistent with Staphylococci and Streptococci species (× 1000) 
In group 3 (72 $\mathrm{h} \mathrm{PMI),} \mathrm{the} \mathrm{pulp} \mathrm{tissue} \mathrm{was} \mathrm{pale} \mathrm{pink}$ with jelly-like consistency. Histologically, almost half of the connective tissue showed degeneration. Reduced cellularity was observed consisting of few fibroblasts showing signs of karyorrhexis. The odontoblastic layer was intact. The blood vessels showed endothelial cell degeneration containing debris of degenerated RBCs. Focal areas of defense cells were seen with lightly stained basophilic nucleus (Fig. 3).

Group 4 with 1 month PMI showed a dehydrated threadlike pulp tissue. The $\mathrm{H} \& \mathrm{E}$ section had stands of the matrix at the center and also at the periphery with large vacuolated areas filling the rest of the stroma. A substantial decrease in fibroblasts with lightly staining karyorrhexis basophilic nucleus was noticed. The odontoblastic layer was seen in few areas at the periphery. Scanty defense cells with lightly stained basophilic nucleus were seen. Blood vessels were not comprehendible hereafter (Fig. 4).

A dried up, whitish friable thread-like pulp tissue was noticed in group 5 (3 months PMI). The microscopic features showed large areas of vacuolations filling up the entire extracellular matrix (ECM) with only thin strands

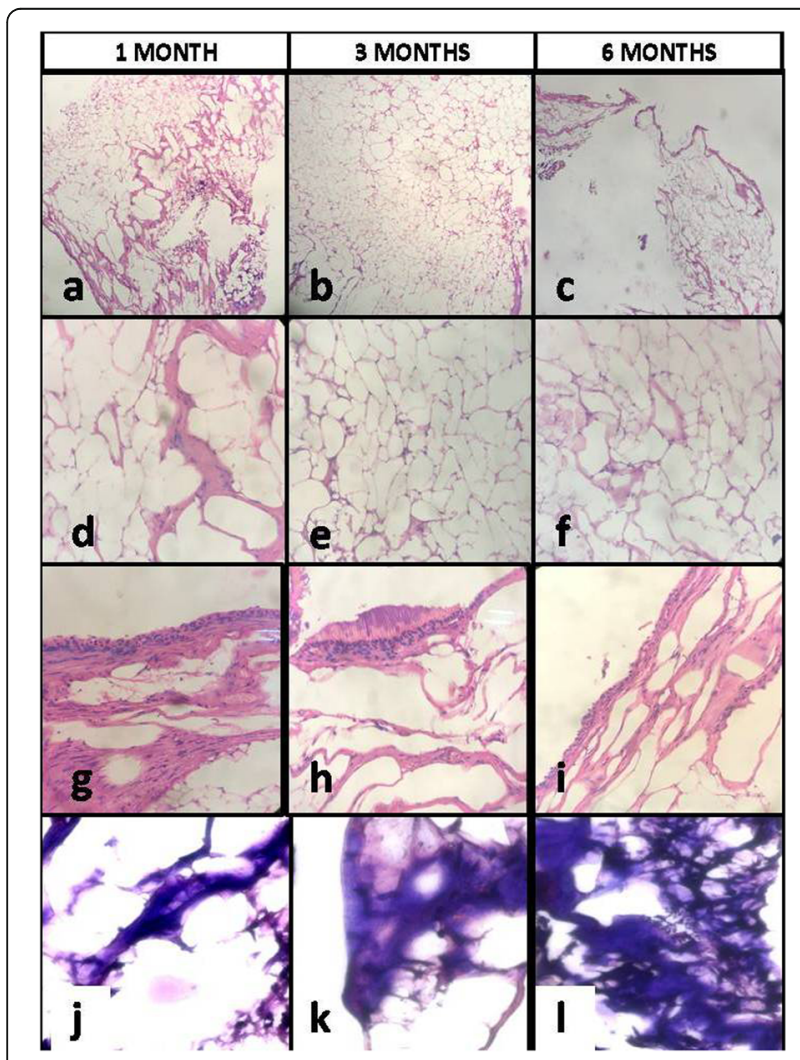

Fig. 4 Histological and microbiological assessment after 1, 3, and 6 months of extraction. $\mathbf{a}-\mathbf{c}$ Increasing vacuolations of the ECM with time $(\times 100)$. $\mathbf{d}-\mathbf{f}$ Degenerating nuclei of the fibroblasts $(\times 400)$. $\mathbf{g}-\mathbf{i}$ Intact odontoblastic layer ( $\times 400)$. j-I Gram stain (Brown and Brenn) showing the presence of Gram-positive cocci of Staphylococcus and Streptococcus species $(\times 1000)$ remaining at the periphery. Negligible number of fibroblasts was observed with lightly basophilic nuclei showing signs of pyknosis. The odontoblastic layer was noticed in a few areas at the periphery. Defense cells were negligible (Fig. 4).

At 6 month PMI (group 6), the pulp was reduced to a thin desiccated frayed thread-like structure. The connective tissue had a negligible matrix with predominantly vacuolated stroma. Few fibroblasts were seen. Defense cells as well as blood vessels were not comprehendible. Odontoblastic layer was seen in a few areas. Scattered nuclear debris was also noticed (Fig. 4).

In both groups 7 and 8 , the retrieved pulp showed peripheral strands and thin streaks of collagen whereas a few nuclear debris was seen only in group 7. There was no evidence of any cellular contents, blood vessels, and defense cells (Fig. 5).

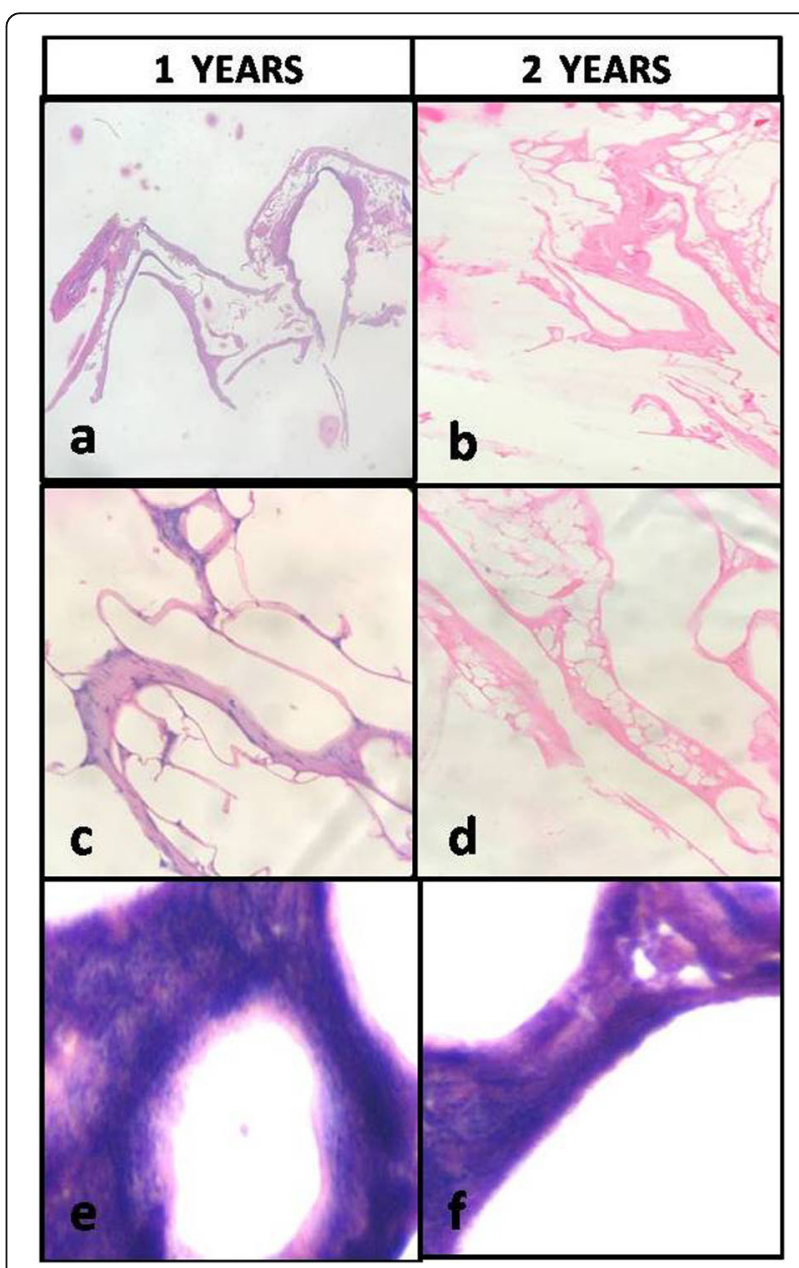

Fig. 5 Histology and microbiology of dental pulp after 1 and 2 years of extraction. $\mathbf{a}, \mathbf{b}$ Thin strands and streaks of EMC seen $(\times 100)$. c Basophilic nuclear debris of the fibroblasts seen $(\times 400)$. d No nuclear debris appreciated $(\times 400)$. e, f Tissue Gram stain (Brown and Brenn) highlighting the presence of Gram-positive Staphylococci and Streptococci $(\times 1000)$ 
The Gram-stained sections of all groups showed focal presence of Gram-positive Staphylococci and Streptococci. The histological and microbiological findings of the study are categorized and charted in Table 1 .

\section{Discussion}

Determination of PMI is an important parameter in forensic evaluation. Considerable morphologic and histologic changes take place in the body after death attributed to the absence of circulation of blood and loss of regulatory mechanisms causing enzymatic dissolution of the injured cells leading to cellular and nuclear degeneration. Diverse histopathologic methods have been employed to identify the characteristic degenerative changes and determine the time elapsed after death in various soft tissues of the body (Zdravković et al. 2006; Pittner et al. 2016; Kushwaha et al. 2010) of which, we found only four studies on histological evaluation of PMI changes in human dental pulp (Gawande et al. 2012; Carrasco et al. 2017; Rajesh et al. 2016; Duffy et al. 1991).

Dental pulp is enclosed in hard tissue and hence it is well protected and preserved for a longer time. Preservation of dental pulp is seen long after damage to other tissues is evident. Thus, it is an ideal tissue for analysis of post-mortem changes. Rajesh et al. (2016) histologically noted the degenerative changes up to $36 \mathrm{~h}$ whereas Gawande et al. (2012) listed the findings up to $96 \mathrm{~h}$ only. A comparative study on the putrefaction rate of dental pulp in extracted teeth of humans, pigs, and unextracted teeth within the jaws of a pig was done by Duffy et al. in northwest coastal climate of Canada until 14 days. Carrasco et al. (2017) attempted to quantify these changes up to 6 months. Ours is a first of its kind study, where we analyzed the tissue morphologic changes, staining characteristics, and structural details in $\mathrm{H}$ \& E-stained pulp tissue harvested at varying time intervals up to 2 years.

The body undergoes putrefaction which is majorly affected by the circumstances of death, external environmental factors, and internal factors of the deceased (Gawande et al. 2012). The relative humidity, the temperature, and the bacterial load of the environment also affect the desiccation of the soft tissue. In our study, to curtail the influence of external factors on pulp tissue, we blocked the apical foramen by a piece of modeling wax. We had kept the tooth at room temperature, the mean being $36^{\circ} \mathrm{C}$. An attempt has been made to estimate the histologic changes in the tooth pulp which is preserved within the hard enclosure of enamel and dentin up to 2 years from the time of extraction which is considered equivalent to the time of death.

The array of methods has been previously described to retrieve the pulp like sectioning the tooth with disk
(Gawande et al. 2012), decalcification (Vavpotic et al. 2009), and using rotary instruments and files (Carrasco et al. 2017). These methods exposed pulp to excessive heat and/or chemicals which could alter the morphologic and histologic characteristics. In our study, we have used a less aggressive method in which the tooth is split with small sharp strokes applied to chisel by a mallet and whole pulp harvested without exposing to chemicals or heat (Fig. 1).

On morphological evaluation, the color of the pulp tissue gradually changed from pink at $24 \mathrm{~h}$ to dirty pink at $48 \mathrm{~h}$ followed by pale pink at $72 \mathrm{~h}$. The consistency ranged from soft to firm to jelly up to $72 \mathrm{~h}$ and later became dehydrated, dried, desiccated, and friable by the end of 2 years (Fig. 2). A similar finding was found in only one study by Mehendiratta et al. (2015) who studied the time-related changes in dental pulp samples of porcine teeth. No evidence of any literature on the morphologic analysis of human pulp was found in postmortem teeth.

Pulp is a soft, vascular connective tissue rich in fibroblasts and defense cells embedded in a soft gelatinous ECM lined by odontoblasts (Goldberg and Hirata 2017). In the present study, the light microscopic features of the degenerative changes in the constituents of pulp have been categorized at varying time intervals for up to 2 years. A rapid degeneration was observed until $72 \mathrm{~h}$. The rate of decomposition had gradually slowed down beyond one month with relatively less histologic variation up to 2 years. This may be attributed to the fact that the desiccation of the pulp tissue after 1 month aids to the preservation of the tissue (Michaud and Foran 2011)

The ECM of pulp consists of a delicate network of collagen fibrils, fibronectin, tenascin, other noncollagenous proteins, and proteoglycans which imparts an eosinophilic background in $\mathrm{H}$ \& E-stained sections of pulp (Goldberg and Hirata 2017). A decline in staining property of the ECM is seen with increasing time. This was in agreement with the study by Gawande et al. but in contrast with observations by Mehendiratta et al. (2015) and Duffy et al. (1991) who documented increased eosinophilic areas and condensation. Few small vacuolations were noted in group 1 samples which progressively increased in size and number in the subsequent groups nearly filling up the entire stroma by 2 years. Identical observations were reported by Mehendiratta et al. (2015), Rajesh et al. (2016), and Carrasco et al. (2017). The release of intracellular hydrolytic enzymes and anaerobic putrefying bacteria causes decomposition of these ECM components producing gas (Mehendiratta $M$ et al. 2015) which might be reflected by these vacuolations. 


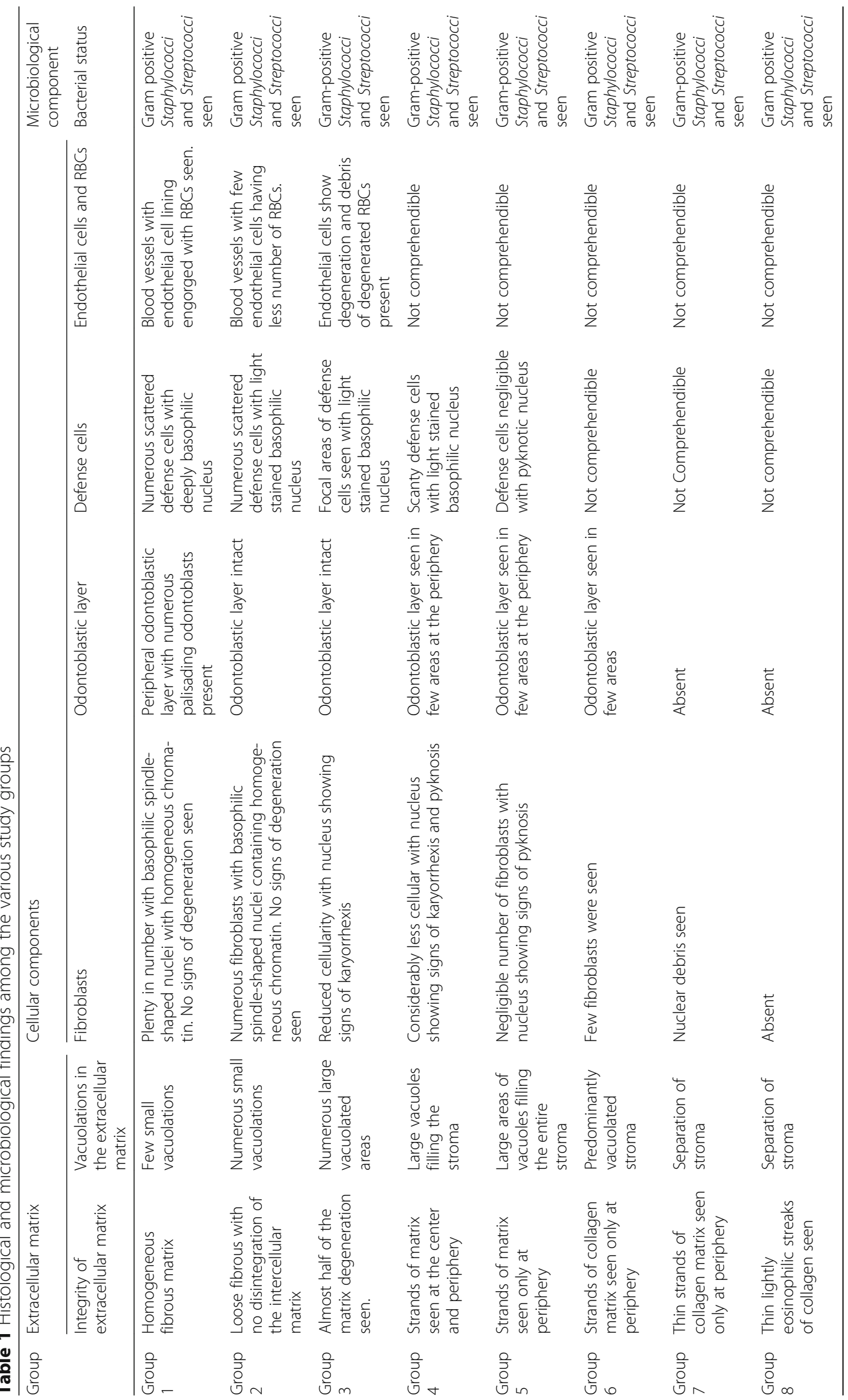


The nuclear density of fibroblasts and defense cells progressively reduced with increasing time interval after which they were diminished to fragmented nuclear debris. These observations were consistent with the findings of the quantitative analysis done by Carrasco et al. (2017). A series of autolytic changes were observed in the nuclei of these cells which included karyorrhexis at $72 \mathrm{~h}$, pyknosis at 1 month, and karyolysis by 6 months. The nuclei of the fibroblasts in our study were comprehendible up to 6 months which was similar to the study by Carrasco et al. (2017). On the other hand, rapid degeneration of the cells with nuclear stability was noted up to $144 \mathrm{~h}$ by Mehendiratta et al. (2015) and 2 weeks by Duffy et al. (1991). This may be attributed to the difference in environmental conditions where the temperature and humidity come into effect. Moreover, in these studies, the samples were buried in the soil which would have accelerated the rate of degeneration due to the favorable bacterial and fungal proliferation. In our study, a temperature of $36^{\circ} \mathrm{C}$ and relatively lower humidity similar to the experiment by Carrasco et al. (2017) would have resulted in desiccation of the pulp tissue leading to longer nuclear stability.

Although our methodology permitted limited preservation of the odontoblastic layer, a layer of odontoblasts with palisading nuclei was seen in the periphery in some areas up to 6 months (Figs. 2 and 3). Nuclear stability of the odontoblasts was also noted till 6 months which slowly declined over time. Vavpotic et al. (2009) found a linear regression model for relative values of odontoblastic density until $120 \mathrm{~h}$.

In the present study, the integrity of the blood vessels and RBCs were seen up to $72 \mathrm{~h}$ after which they were not discernable. Mehendiratta et al. (2015) in their study found faint outlines of blood vessels with few endothelial cells remaining in subsurface samples at $96 \mathrm{~h}$. The blood vessel parameter can prove as a useful tool to estimate early PMI.

On the microbiological assessment of the tissue sections with Gram stain, Gram-positive Staphylococci and Streptococci were noticed in all groups of study. Hyde et al. (2013) have documented a shift in the nature of bacteria from aerobic like Staphylococcus and Enterobacteriacae to anaerobic like Clostridia and Bacteroides in cadavers. They further noticed Streptococcus among the top ten genera in the pre bloat swab of mouth samples in human remains. There are no studies to date on the microbiological flora of the post-mortem decomposing pulp.

This study was limited to a small sample size of 40 teeth and the study design being qualitative analysis. Since literature pertaining to the topic was sparse with no satisfactorily conclusive results, we conducted this observational study to analyze the exploratory possibilities with a small sample size and charted our findings. Further researches on a larger sample size can be done to quantitatively analyze and standardize these qualitative characteristics.

In the present study, the unfixed ante-mortem pulp tissue simulates the autolytic changes which take place in a post-mortem tissue. This study has its scope where the remains of the deceased could be studied at diverse circumstances and climatic conditions. It would also be interesting to carry out studies pertaining to the time to which successful DNA extraction can be done from the nuclei of the pulp in different environmental conditions. This can provide information on the identity of the individual which will be valuable in forensic investigation.

\section{Conclusion}

Dental pulp organ which is enclosed within the hardest structure is preserved for a longer time in contrast to other soft tissues of the body which is exposed to diverse external factors. Estimation of PMI has its significance and implication in a forensic and criminal investigation. The histologic traits of various organs of the body have been extensively studied. These tissues can only be approximately discernable for up to 5 days, whereas PMI from dental pulp can be estimated up to 2 years histomorphologically as documented in our study. We noticed progressive degradation of the pulpal matrix with increased vacuolations and reduced cellularity with increasing post-mortem time interval. Gram-positive bacterial colonies were seen in all groups of studies. This progressive transformation of the morphological and histological characteristics of the intercellular matrix and cellular components can prove to be a simplified, costeffective, and reliable additional tool in forensic pathology to estimate the post-mortem interval.

\section{Abbreviations}

ECM: Extracellular matrix; H \& E: Hematoxylin and eosin; PMI: Post-mortem interval; RBCs: Red blood cells

Acknowledgements

Not applicable.

\section{Authors' contributions \\ LB and SSB contributed to the design of the study and drafting of the manuscript. KCD, PM, NM, and AP contributed towards the morphologic, histologic, and microbiologic assessment. All authors have read and approved the final manuscript.}

Funding

Not applicable.

Availability of data and materials Not applicable.

Ethics approval and consent to participate

Ethical approval has been obtained from Institutional Ethics Committee, Kalinga Institute of Dental Sciences. A specially designed informed consent was obtained from the participants participating in the study. 


\section{Consent for publication}

Not applicable.

\section{Competing interests}

The authors declare that they have no competing interests.

Received: 2 March 2020 Accepted: 23 June 2020

Published online: 03 July 2020

\section{References}

Carrasco PA, Brizuela Cl, Rodriguez IA, Muñoz S, Godoy ME, Inostroza C (2017) Histological transformations of the dental pulp as possible indicator of post mortem interval: a pilot study. Forensic Sci Int 279:251-257. https://doi.org/ 10.1016/j.forsciint.2017.09.001 Epub 2017 Sep 11

Duffy JB, Skinner MF, Waterfield JD (1991) Rates of putrefaction of dental pulp in the Northwest coast environment. J Forensic Sci 36:1492-1502

Gawande M, Chaudhary M, Das A (2012) Estimation of the time of death by evaluating histological changes in the pulp. Indian J Forensic Med Toxicol 6:80-82

Goldberg M, Hirata A (2017) The dental pulp: composition, properties and functions. JSM Dent 5:1079

Hyde ER, Haarmann DP, Lynne AM, Bucheli SR, Petrosino JF (2013) The living dead: bacterial community structure of a cadaver at the onset and end of the bloat stage of decomposition. PLoS One 8(10):e77733. https://doi.org/10. 1371/journal.pone.0077733

Kushwaha V, Yadav M, Srivastava AK, Agarwal A (2010) Time since death from degenerative changes in the Kidney. J Indian Acad Forensic Med 32(1):37-41

Manoilescu I, lon A, loan BG (2015) Post-Mortem changes in teeth - forensic issues. International Journal of Medical dentistry 5:249-252

Mehendiratta M, Jain K, Boaz K, Bansal M, Manaktala N (2015) Estimation of time elapsed since the death from identification of morphological and histological time-related changes in dental pulp: an observational study from porcine teeth. Journal of forensic dental sciences 7:95-100. https://doi.org/10.4103/ 0975-1475.154594

Michaud CL, Foran DR (2011) Simplified field preservation of tissues for subsequent DNA analyses. J Forensic Sci. 56:846-852

Pittner S, Monticelli FC, Pfisterer A, Zissler A, Sänger AM, Stoiber W, Steinbacher P (2016) Postmortem degradation of skeletal muscle proteins: a novel approach to determine the time since death. Int J Legal Med. 130(2):421-431

Rajesh R, Pradhan P, Sampath KP, Malathi N (2016) Estimation of time of death from histopathology of dental pulp - an autopsy based study. Int J Med Toxicol Legal Med 19(3):43-45

Vavpotic M, Turk T, Martincic DS, Balazic J (2009) Characteristics of the number of odontoblasts in human dental pulp post-mortem. Forensic Sci Int. 193:122-126

Zdravković M, Kostov M, Stojanović M (2006) Identification of postmortem autolytic changes on the kidney tissue using pas stained method. Med Biol 13:181-184

\section{Publisher's Note}

Springer Nature remains neutral with regard to jurisdictional claims in published maps and institutional affiliations.

\section{Submit your manuscript to a SpringerOpen ${ }^{\circ}$ journal and benefit from:}

- Convenient online submission

- Rigorous peer review

- Open access: articles freely available online

- High visibility within the field

- Retaining the copyright to your article

Submit your next manuscript at $\boldsymbol{\nabla}$ springeropen.com 